\title{
Surgery of fullerenes
}

$\operatorname{AUTHOR}(S)$ :

Murata, Michihisa; Murata, Yasujiro; Komatsu, Koichi

\section{CITATION:}

Murata, Michihisa ...[et al]. Surgery of fullerenes. Chemical

Communications 2008, 46: 6083-6094

\section{ISSUE DATE:}

2008-12-14

URL:

http://hdl.handle.net/2433/85298

\section{RIGHT:}

Chem. Commun., 2008, pp.6083-6094 - Reproduced by permission of The Royal Society of Chemistry (RSC); 許諾条件により本文は2009-12-14に公開; This is not the published version. Please cite only the published version.; この論文は出版社版でありません。引用 の際には出版社版をご確認ご利用ください。 


\title{
Surgery of fullerenes
}

\author{
Michihisa Murata, ${ }^{a}$ Yasujiro Murata, ${ }^{a, b}$ and Koichi Komatsu ${ }^{* c}$ \\ Received (in XXX, XXX) 1st January 2007, Accepted 1st January 2007 \\ First published on the web 1st January 2007 \\ ${ }_{5}$ DOI: $10.1039 / \mathbf{b 0 0 0 0 0 0 x}$
}

Recent attempts at the synthesis of endohedral fullerenes by organic reactions, so-called "molecular surgery" methods, are surveyed. The creation of an opening on the surface of fullerene cages allowed insertion of $\mathrm{He}, \mathrm{H}_{2}, \mathrm{H}_{2} \mathrm{O}$, or $\mathrm{CO}$ within the cages. An effective route to "suture" an opening was established to realize new endohedral fullerene, $\mathrm{H}_{2} @ \mathrm{C}_{60}$. Further development of this 10 operation as well as the properties and reactions of $\mathrm{H}_{2} @ \mathrm{C}_{60}$ are summarized. Also the application of the encapsulated $\mathrm{H}_{2}$ molecule as an NMR probe for the study of aromaticity of ionic fullerenes is described.

\section{Introduction}

Endohedral fullerenes, which encapsulate atom(s) or small 15 molecule(s) within the spherical carbon cage, have attracted much attention from viewpoints of not only fundamental curiosity but also applied studies because of their unique electronic structures resulting from the interaction between the fullerene $\pi$-system and incorporated species. ${ }^{1-3}$

20 The fullerenes encapsulating metal atom(s), so-called endohedral metallofullerenes, were first produced by laservaporization of graphite-metal oxides composite materials at the early stage of fullerene research, and later by the use of arc discharge technique. ${ }^{1-3}$ In these metallofullerenes,

${ }^{a}$ Institute for Chemical Research, Kyoto University, Uji, Kyoto 611-0011, Japan.

${ }^{b}$ PRESTO, Japan Science and Technology Agency.

${ }^{c}$ Department of Environmental and Biotechnological Frontier Engineering, Fukui University of Technology, Gakuen, Fukui 910-8505, Japan. E-mail: komatsu@fukui-ut.ac.jp; Fax: (+81) 75-761-8089; Tel: (+81) 75-761-8039
25 electron transfer from the incorporated metal atom(s) to the fullerene cage gives rise to characteristic behaviors which are totally different from those of empty fullerenes. Just for example as a representative case, La@ $\mathrm{C}_{82}$ (@ denotes that the $\mathrm{La}$ is encapsulated within the $\mathrm{C}_{82}$ cage) should be better 30 described as $\mathrm{La}^{3+} @ \mathrm{C}_{82}{ }^{3-}$ because of the electron transfer to endow La@ $\mathrm{C}_{82}$ with paramagnetic character. The redox behaviors of $\mathrm{La} @ \mathrm{C}_{82}$, studied by cyclic voltammetry, revealed that abilities both as an electron acceptor and as a donor are higher than that of empty $\mathrm{C}_{82}{ }^{4}$ Furthermore, La@ $\mathrm{C}_{82}$ can be 35 regarded as a "super atom", since one-electron oxidation or reduction was shown to take place on the $\mathrm{C}_{82}$ cage while keeping the positive charge of the La atom constant. ${ }^{5}$

It should also be noted that chemical and physical properties of fullerenes encapsulating a trimetallic nitride 40 cluster such as $\mathrm{Sc}_{3} \mathrm{~N} @ \mathrm{C}_{80}$ have been investigated in detail since its discoverly by Dorn. ${ }^{6}$ In particular, $\mathrm{Sc}_{3} \mathrm{~N} @ \mathrm{C}_{80}$ was shown to be even applicable as a part of an electrondonor/acceptor system.

Recently, effort was made to develop highly efficient MRI 45 (magnetic resonance imaging) contrast agents by the use of
Michihisa Murata was born in Kyoto, Japan, in 1978. He studied the chemistry of fullerenes at Kyoto University and received his Ph.D. degree under the supervision of Koichi Komatsu in 2006. After working as a researcher at Kaneka Corp., Japan, he returned to Kyoto. He is currently an Assistant Professor at Institute for Chemical Research of Kyoto University. He has been awarded Inoue Research Award for Young Scientists in 2008. His research interests are in the area of chemistry on novel organic molecules with curved $\pi$-conjugated systems.

Yasujiro Murata was born in Kanazawa, Japan in 1970. He studied chemistry at Kyoto University, Japan, and received his Ph. D. degree under the supervision of Koichi Komatsu in 1998. During that time he joined Fred Wudl's group as a summer student in 1995. After working as a postdoctoral fellow at Kyoto University in Komatsu's group, he joined Institute for Chemical Research, Kyoto University, as an Assistant Professor during 1999-2006 and then as an Associate Professor since 2006. In 2004, he received The Chemical Society of Japan Award for
Young Chemists. His research interests include the synthesis of fullerene derivatives having novel structures and properties.

Koichi Komatsu, FRSC, was born in Kyoto, Japan, in 1942. He studied the synthesis and properties of carbocations at Kyoto University and received his Ph.D. degree under the supervision of Kunio Okamoto in 1974. After postdoctoral work with Robert West in University of Wisconsin, USA, during 1975-1976, he returned to Kyoto. After serving as an assistant professor, lecturer, and associate professor, he was promoted to professor at Institute for Chemical Research of Kyoto University in 1995. He has been awarded the Divisional Award of The Chemical Society of Japan, Alexander von Humboldt Research Award, and the Chemical Society of Japan Award. In 2006 he retired from Kyoto University and moved to Fukui University of Technology as professor. His research interest is focused on the synthesis and properties of novel two- and three-dimensional $\pi$-conjugated systems. 
water-soluble fullerene derivatives encapsulating a paramagnetic $\mathrm{Gd}(\mathrm{III})$ ion. ${ }^{8}$ Besides the high performance as the contrast agent, the Gd(III)-incorporated fullerenes are of great significance from the viewpoint of safety because toxic ${ }_{5} \mathrm{Gd}(\mathrm{III})$ ion is entirely isolated by the encapsulation in the fullerene cage.

Furthermore, small band gaps of endohedral metallofullerenes make them potential candidates for practical use, for example, in the field of molecular electronics such as 10 thin film organic field effect transistor. Actually, endohedral metallofullerens such as $\mathrm{La}_{2} @ \mathrm{C}_{80}{ }^{9}$ or nanorods of La@ $\mathrm{C}_{82}(\mathrm{Ad})^{10}(\mathrm{Ad}=$ adamantylidene $)$ have been shown to exhibit the FET properties.

However, development of such applications has so far been 15 hampered by severe limitations of their availability that relied on the hard-to-control method of production. The conventional methods, i.e. arc-discharge or laser vaporization of graphite rods containing metal oxides or carbides, have almost no selectivity in controlling both the cage-size and 20 product distribution. Generally, a pure product can be available only in mg-quantities after tedious separation procedures.

As another types of endohedral fullerenes, fullerenes encapsulating a noble-gas atom, such as helium, neon, argon, 25 krypton, and even xenon were realized by Saunders by treating the fullerene powder under forced conditions $\left(650{ }^{\circ} \mathrm{C}\right.$ and $3000 \mathrm{~atm}$ of noble gases). ${ }^{11}$ Although the occupation level of guest is so low as $0.1 \%,{ }^{12}$ incorporation of an NMR active nucleus, ${ }^{3} \mathrm{He}$, within fullerene cages has proven to be 30 useful because it provides valuable information about magnetic shielding effect inside the fullerenes caused by ring currents of the spherically delocalized $\pi$-electrons. ${ }^{13,14}$ The NMR signal of ${ }^{3} \mathrm{He}$ is also useful as a tool to follow chemical reactions taking place at the exterior of the fullerene cages. ${ }^{15}$

35 Recent investigation revealed that the reactivity of Xe@ $\mathrm{C}_{60}$ in [4+2] cycloaddition with 9,10-dimethylanthracene is substantially different from that of $\mathrm{He} @ \mathrm{C}_{60}$ because $\pi$ electron cloud of the $\mathrm{C}_{60}$ cage is pushed outward by the inside xenon atom. ${ }^{16}$ However, a low occupation level of the noble${ }_{40}$ gas atom within fullerenes (about $0.1 \%$ ) and difficulty in isolation or enrichment in practical scale ${ }^{17}$ have apparently hampered the exploration of possibility of the endohedral fullerenes as functional materials. Hence, it is desirable to explore an entirely different approach that would lead to the 45 macroscopic production of endohedral fullerenes.

\section{Open-cage fullerenes}

Under such circumstances it is quite appealing to produce the endohedral fullerenes by using pristine fullerenes as starting materials. In this connection, Rubin proposed a concept to 50 realize endohedral fullerenes with the use of organic reactions, that is, "molecular surgery". ${ }^{18}$ This approach consists of a series of steps, which are (1) "incision" of the fullerene cage to form an opening on the surface, (2) insertion of some small atom(s) or molecule(s) through the opening, and (3) "suture" 55 of the opening to reproduce the fullerene cage while retaining the guest species.

The development of this approach has been a challenging task for organic chemists for the past decade. Wudl reported, for the first time, two-step reactions to create an 1160 membered-ring opening on the $\mathrm{C}_{60}$ cage to give compound 1. ${ }^{19}$ Unfortunately, however, the opening was found to be not large enough even for the smallest atom, helium, to pass through. ${ }^{20}$ Rubin thereafter synthesized bisfulleroid derivative $\mathbf{2}$ with an eight-membered-ring opening and 65 transformed it into Co(III) complex 3 . $^{21}$ These works are unequivocally a stepping stone to the subsequent progress in the technique of incising the fullerene cage. Herein, we summarize recent achievements in the molecular surgical technique with the hope of encouraging the progress in

70 research on the rational chemical synthesis as well as the application of endohedral fullerenes.

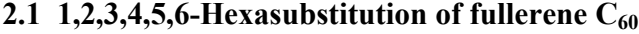

Rubin proposed a strategy ${ }^{18}$ toward "incising" a fullerene cage through saturation of three adjacent $\mathrm{C}=\mathrm{C}$ double bonds within 75 one hexagonal ring. The subsequent $[2+2+2]$ cycloreversion of the planarized cyclohexane ring was expected to give a fullerene derivative with such a large opening as a 15membered ring (Fig. 1). Thus, a thermal reaction of $\mathrm{C}_{60}$ with butadiene derivative $\mathbf{4}$ having two azido groups was 80 conducted. $^{22}$ This reaction was intended to proceed via initial addition of 4 (involving both a [4+2] cycloaddition and two 1,3-dipolar additions) to the three $\mathrm{C}=\mathrm{C}$ double bonds in the same hexagon of $\mathrm{C}_{60}$ to form compound 5 with a saturated cyclohexane ring. However, the obtained product was instead 85 bislactam 6 having a 14-membered-ring opening produced through a series of reactions involving rearrangements, extrusion of two $\mathrm{N}_{2}$ molecules, and addition of an $\mathrm{O}_{2}$ molecule followed by dehydrogenation. ${ }^{22}$

The synthesis of bislactam $\mathbf{6}$ is of considerable significance 90 because the size of the opening was proved to be large enough for the first time for insertion of the smallest gaseous species such as a ${ }^{3} \mathrm{He}$ atom or a $\mathrm{H}_{2}$ molecule. ${ }^{23}$ By treating a crystalline powder of 6 with $475 \mathrm{~atm}$ of ${ }^{3} \mathrm{He}$ gas at $288-305^{\circ} \mathrm{C}$ for 7.5 hours, a ${ }^{3} \mathrm{He}$ atom was incorporated at an occupation ${ }_{5}$ level of $1.5 \%$. $\mathrm{A}_{2}$ molecule was also introduced at an occupation level of $5 \%$ under the conditions of $100 \mathrm{~atm}$ of $\mathrm{H}_{2}$ gas at $400{ }^{\circ} \mathrm{C}$ for 48 hours. A highly shielded ${ }^{1} \mathrm{H}$ NMR signal for the encapsulated $\mathrm{H}_{2}$ was observed at $\delta=-5.43 \mathrm{ppm}$. These results verified the feasibility of the strategy of 100 molecular surgery approach.

Recently, Rubin succeeded in the synthesis of the desired 1,2,3,4,5,6-hexaadduct of $\mathrm{C}_{60}, 7$, by the reaction of bisisobenzofuran adduct 8 with $\mathrm{Pb}(\mathrm{OAc})_{4}$ in a substantially low concentration $\left(1.0 \times 10^{-5} \mathrm{M}\right){ }^{24}$ Unfortunately, however, the 105 retro $[2+2+2]$ ring-opening reaction at the strained cyclohexane ring of 7 to afford open-cage fullerene $\mathbf{9}$ did not take place due to the high activation barrier for this transformation and the thermal instability of product 9 as indicated by theoretical calculations (B3LYP/6-31G*//PM3 10 level). The origin of the high endothermicity of this ringopening reaction is attributable to the formation of two strained $\mathrm{C}=\mathrm{C}$ double bonds in oxabenzonorbornadiene moieties of 9 .

\subsection{Bowl-shaped fullerenes}


Bisfulleroid derivative $2,{ }^{21}$ synthesized by Rubin, possesses bridgehead $\mathrm{C}=\mathrm{C}$ double bonds at the rim of the eightmembered-ring opening. Komatsu and Iwamatsu independently found that one of these double bonds in the 5 derivatives of $\mathbf{2}$ : i.e., $\mathbf{1 0}^{25}$ and $\mathbf{1 1}^{26}$, can be readily cleaved via addition of photochemically generated singlet oxygen to give diketone derivatives $\mathbf{1 2}^{25}$ and $\mathbf{1 3},{ }^{27}$ respectively, with a 12 membered-ring opening. ${ }^{28}$

The formation of $\mathbf{1 2}$ led to the successful achievement of 10 "molecular sugery" as will be shown later, while derivative $\mathbf{1 3}$ was found to be a good precurser of various bowl-shaped fullerenes. $^{29}$

Thus, the opening of diketone $\mathbf{1 3}$ was greatly enlarged as reported by Iwamatsu. Although the detailed reaction 15 mechanism is not clear yet, a reaction of $\mathbf{1 3}$ with a phenyl hydrazine proceeded at room temperature to give open-cage fullerene $\mathbf{1 4}$ having an $\mathrm{sp}^{3}$ methylene carbon within the rim of a 16-membered-ring opening. ${ }^{30}$ The size of the ellipsoidal opening was estimated to be $6.5 \AA$ for a longer axis and $3.8 \AA$ 20 for a shorter axis $(\mathrm{B} 3 \mathrm{LYP} / 3-21 \mathrm{G}$ level). When a solution of 14 in 1,1,2,2-tetrachloroethane- $d_{2}\left(\right.$ TCE- $\left.d_{2}\right)$ was heated under $133 \mathrm{~atm}$ of $\mathrm{H}_{2}$ gas at $100{ }^{\circ} \mathrm{C}$ for 4 hours, encapsulation of $\mathrm{a}_{2}$ molecule took place to give $\mathrm{H}_{2} @ \mathbf{1 4}$ at an occupation level of $62 \%{ }^{31}$ Since the activation barrier for the escape of 25 encapsulated $\mathrm{H}_{2}$ is only $23.7 \mathrm{kcal} / \mathrm{mol}$ reflecting the large opening of 14 , release of the $\mathrm{H}_{2}$ molecule gradually occurred even at room temperature with the half-life of roughly one month.

Although until then the species encapsulated in the open30 cage fullerenes had been limited to a $\mathrm{He}$ atom or a $\mathrm{H}_{2}$ molecule, significant progress was made by Iwamatsu in 2004 when he created a huge opening on $\mathrm{C}_{60}$ cage. ${ }^{32}$ The opening of diketone 13 was greatly enlarged by the reaction with a 1,2phenylenediamine derivative affording a bowl-shaped 35 compound 15 with a 20 -membered-ring opening. The size of the opening was calculated to be $6.5 \AA$ for a longer axis and $4.2 \AA$ for a shorter axis (B3LYP/6-31G* level). Surprisingly, upon ${ }^{1} \mathrm{H}$ NMR measurement of $\mathbf{1 5}$ in TCE- $d_{2}$, a sharp singlet signal was observed at such a high field as $\delta=-11.4 \mathrm{ppm}$ 40 even without any intentional procedure for guest incorporation. This signal was assigned to an $\mathrm{H}_{2} \mathrm{O}$ molecule encapsulated in 15 based on the results of a $\mathrm{D}_{2} \mathrm{O}$ exchange experiment together with elemental analysis. Encapsulation and release of the $\mathrm{H}_{2} \mathrm{O}$ molecule in $\mathbf{1 5}$ is in equilibrium in TCE- $d_{2}$, as ${ }_{45}$ demonstrated by variable-temperature NMR measurements. They showed the occupation level of the $\mathrm{H}_{2} \mathrm{O}$ molecule to reach $75 \%$ at ambient temperature while it decreased at higher temperatures. Furthermore, it was demonstrated that the bowl-shaped compound $\mathbf{1 5}$ is able to incorporate a $\mathrm{CO}$ ${ }_{50}$ molecule within the cage. ${ }^{33}$ Upon heating a solution of $\mathrm{H}_{2} \mathrm{O} @ 15$ in TCE- $d_{2}$ under $89 \mathrm{~atm}$ of $\mathrm{CO}$ gas at $100{ }^{\circ} \mathrm{C}$ for 20 hours, replacement of the $\mathrm{H}_{2} \mathrm{O}$ molecule inside $\mathbf{1 5}$ by a $\mathrm{CO}$ molecule took place to give $\mathrm{CO} @ \mathbf{1 5}$ at an occupation level of $84 \%$. The ${ }^{13} \mathrm{C}$ NMR signal of the encapsulated $\mathrm{CO}$ was 55 observed at $\delta=174.3 \mathrm{ppm}$ in TCE- $d_{2}$, which is $10 \mathrm{ppm}$ upfield shifted relative to a signal of dissolved $\mathrm{CO}$ gas $(\delta=$ 184.6 ppm in $\left.\mathrm{CDCl}_{3}\right)$. The IR spectrum of $\mathrm{CO} @ 15$ exhibited two absorptions at $v=2125$ and $2112 \mathrm{~cm}^{-1}$ indicating that there exist two orientations in the encapsulated $\mathrm{CO}$ molecule 60 on the time scale of the IR measurement. When $\mathrm{CO} @ \mathbf{1 5}$ was kept in a solution of $\mathrm{CDCl}_{3}$ in the presence of water at $40{ }^{\circ} \mathrm{C}$, the encapsulated $\mathrm{CO}$ molecule was gradually released from the cage with concomitant formation of $\mathrm{H}_{2} \mathrm{O} @ 15$ instead. This result indicates that the encapsulation of an $\mathrm{H}_{2} \mathrm{O}$ ${ }_{65}$ molecule within $\mathbf{1 5}$ is thermodynamically more favored than that of a CO molecule.

The bowl-shaped compounds such as $\mathbf{1 4}$ and $\mathbf{1 5}$ derived from $\mathrm{C}_{60}$ are quite attractive as novel host molecules. However, from the viewpoint of "molecular surgery 70 operation", these compounds have a definite drawback that the restoration of such a severely ruptured $\pi$-system to the original structure of $\mathrm{C}_{60}$ seems almost impossible by means of organic synthetic procedures.

\subsection{Peroxide-mediated formation of open-cage fullerenes}

75 On the other hand, an approach to other types of an open-cage fullerene using entirely different processes has been reported by Gan and coworkers. ${ }^{34}$

They recently reported that the reaction of fullerene $\mathrm{C}_{60}$ with $t$-butyl hydroperoxide in the presence of ceric ammonium 80 nitrate gives hexaadduct $16 .{ }^{35}$ Subsequent oxidation of $\mathbf{1 6}$ by irradiation with visible light in the presence of iodine resuled in the cleavage of the central five-membered-ring and afforded diketone $\mathbf{1 7}$ with a nine-membered-ring opening. ${ }^{36}$ The epoxide moiety in $\mathbf{1 7}$ was transformed to vicinal diol by 85 the use of a Lewis acid, $\mathrm{B}\left(\mathrm{C}_{6} \mathrm{~F}_{5}\right)_{3}$, giving $\mathbf{1 8}$.

Although attempted oxidation of the vicinal diol moiety in 18 was unsuccessful, aminoketal/hemiketal derivative $\mathbf{1 9}$, obtained from the reaction of $\mathbf{1 8}$ with aniline, was found to undergo complex oxidation reactions with 90 diacetoxyliodobenzene. That is, the three hydroxyl groups and the amino group of $\mathbf{1 9}$ were all oxidized to give product 20 with a large opening divided by an acid anhydride bridge. When 20 was reacted with hydrazine, the bridge across the opening could be cleaved to give compounds 21 and 22 95 having an 18-membered-ring opening. The amide group of $\mathbf{2 1}$ was converted to a bromoazocarbonyl moiety by the reaction with $\mathrm{Br}_{2}$ to give $\mathbf{2 3}$, and then the reaction of $\mathbf{2 3}$ with $\mathrm{AgClO}_{4}$ resulted in elimination of the azo-oxo group to afford tri-oxo open-cage fullerene 24 . $^{34}$

100 Upon ${ }^{1} \mathrm{H}$ NMR measurement of $\mathbf{2 4}$ in $\mathrm{CDCl}_{3}-\mathrm{CS}_{2}$ (1:1), a highly shielded signal was observed at $\delta=-13.07 \mathrm{ppm}$. Based on the similarity of the chemical shift to that of $\mathrm{H}_{2} \mathrm{O} @ 15(\delta=-11.4 \mathrm{ppm})$ described above, the signal was assigned to an encapsulated $\mathrm{H}_{2} \mathrm{O}$ molecule, although the 105 occupation level was less than only $5 \% .{ }^{34}$

The size of the opening of $\mathbf{2 4}$ was further expanded by treatment with trifluoroacetic acid in the presence of ferrocene. This reaction removed two $t$-butyl peroxy groups to create an aromatic hexagon, accompanied by insertion of an oxygen 110 atom into the rim of the opening to give $\mathbf{2 5}$ possessing a 19membered-ring opening. It is not surprising that the ${ }^{1} \mathrm{H}$ NMR spectrum of $\mathbf{2 5}$ exhibited an intense signal of an encapsulated $\mathrm{H}_{2} \mathrm{O}$ molecule at $\delta=-12.8 \mathrm{ppm}$ in $\mathrm{CDCl}_{3}$. The occupation level of the $\mathrm{H}_{2} \mathrm{O}$ molecule inside 25 was $57 \%$ at room 115 temperature and it increased up to $88 \%$ upon keeping the 
solution at $-20{ }^{\circ} \mathrm{C}$ for several days. The encapsulated $\mathrm{H}_{2} \mathrm{O}$ molecule within the fullerene cage of $\mathbf{2 4}$ and $\mathbf{2 5}$ was also unambiguously confirmed by the X-ray crystallography.

\section{Molecular surgical method to endohedral fullerenes}

\subsection{Cage opening}

In this section, we will show a series of reactions which led us to the first successful organic synthesis of endohedral fullerene encapsulating molecular hydrogen according to the 10 molecular surgical method.

As has been mentioned above, we synhesized the opencage fullerene $\mathbf{1 2}$ by the reaction of open-cage fullerene $\mathbf{1 0}$ with photochemically generated singlet oxygen. Compound 10 with an 8-membered-ring opening was obtained by the 15 reaction of $\mathrm{C}_{60}$ with 5,6-diphenyl-3-(2-pyridyl)-1,2,4-triazine in $85 \%$ yield based on consumed $\mathrm{C}_{60}(59 \%$ conversion). However, the 12-membered-ring opening in $\mathbf{1 2}$ was not large enough even for a molecule of $\mathrm{H}_{2}$ to pass through as indicated by calculated high activation energy $(51.8 \mathrm{kcal} / \mathrm{mol})$ 20 (B3LYP/6-31G**//B3LYP/3-21G level), and further enlargement of the opening was necessary.

For this purpose, we discovered a novel reaction to insert a sulfur atom into the rim of the opening in $\mathbf{1 2} .^{25}$ Since the electrochemistry indicated that compound $\mathbf{1 2}$ with two ${ }_{25}$ carbonyl groups is even a better $\pi$-electron acceptor than $\mathrm{C}_{60}$, 12 was expected to be activated by a typical electron donor such as tetrakis(dimethylamino)ethylene (TDAE). Thus, in the presence of TDAE 12 was found to react with elemental sulfur in 1,2-dichlorobenzene (ODCB) at $180{ }^{\circ} \mathrm{C}$ to give 30 compound $\mathbf{2 6}^{37}$ having a 13 -membered-ring opening as a single product in $77 \%$ yield. $^{25}$ The structure of $\mathbf{2 6}$ was unambiguously proved by X-ray crystallography. The size of the opening of 26 was $5.64 \AA$ for a longer axis and $3.75 \AA$ for a shorter axis. The calculated activation energy (B3LYP/6-

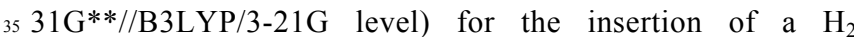
molecule through the opening of $26(30.1 \mathrm{kcal} / \mathrm{mol})^{38}$ was lower than that calculated for bislactam $6(41.4 \mathrm{kcal} / \mathrm{mol})^{23}$ in support of the larger opening of 26. Thus, the encapsulation of a $\mathrm{H}_{2}$ molecule to $\mathbf{2 6}$ was expected to be easier.

The enlargement of the opening of $\mathbf{1 2}$ was also found to be possible by insertion of a selenium atom in place of sulfur to the rim of the opening. ${ }^{39}$ In this case, stronger activation by the use of sodium alkanethiolate as a reducing agent was needed. Thus, the reaction of $\mathbf{1 2}$ with elemental selenium in 45 the presence of $\mathrm{CH}_{3} \mathrm{SNa}$ in refluxing ODCB afforded opencage fullerene 27 in $46 \%$ yield. The results of X-ray crystallography showed that the size of the opening in $\mathbf{2 7}$ was $5.72 \AA$ for a longer axis and $3.88 \AA$ for a shorter axis, which was slightly larger than that of sulfur analogue $26 .{ }^{25}$

\section{${ }_{50} 3.2$ Incorporation of a $\mathrm{H}_{2}$ molecule}

As a guest molecule to be encpsulated in an open-cage fullerene, the smallest molecule, $\mathrm{H}_{2}$, was selected. When open-cage fullerene $\mathbf{2 6}$ was treated with high-pressure $\mathrm{H}_{2}$ gas (800 atm) at $200{ }^{\circ} \mathrm{C}$ for 8 hours in an autoclave, the ${ }_{55}$ incorporation of hydrogen inside the cage was realized. ${ }^{38}$ The
${ }^{1} \mathrm{H}$ NMR of the resulting material in ODCB- $d_{4}$ showed an intense signal of the encapsulated $\mathrm{H}_{2}$ molecule at $\delta=-7.25$ $\mathrm{ppm}$. The integrated intensity of this signal relative to one of the pyridyl proton signals demonstrated that exactly $100 \%$ 60 encapsulation had been achieved. For a selenium analogue 27 with a slightly larger opening, the $100 \%$ insertion of a $\mathrm{H}_{2}$ molecule was achieved under slightly milder conditions, that is, with $760 \mathrm{~atm}$ of $\mathrm{H}_{2}$ gas at $190{ }^{\circ} \mathrm{C}^{39}$

In order to directly observe the encapsulated $\mathrm{H}_{2}$ ${ }_{65}$ molecule $^{38}$ inside the cage, we conducted an X-ray diffraction study of a single crystal of $\mathrm{H}_{2} @ \mathbf{2 6}$, together with empty $\mathbf{2 6}$ as a matching reference, by using synchrotron radiation in Photon Factory at High-Energy Accelerator Research Organization (KEK), Japan, in collaboration with Sawa. ${ }^{41}$ ${ }_{0}$ The resulting electron-density representations of $\mathrm{H}_{2} @ \mathbf{2 6}$ as well as empty $\mathbf{2 6}$ obtained by analysis with a maximum entropy method (MEM) are shown in Fig. 2 as contour maps. These representations clearly demonstrate the electron density that is "floating" at the center of the fullerene cage of $\mathrm{H}_{2} @ \mathbf{2 6}$, 75 while such electron density was not observed at all in the case of empty 26. The number of electrons of this fragment was calculated to be $2.0 \pm 0.1$, exactly corresponding to that of one $\mathrm{H}_{2}$ molecule.

Although $\mathrm{H}_{2} @ 26$ was stable at room temperature, 80 encapsulated $\mathrm{H}_{2}$ was gradually released upon heating its solution in ODCB at the temperatures above $160{ }^{\circ} \mathrm{C}$. The activation energy for the release of the $\mathrm{H}_{2}$ molecule from the cage of $\mathrm{H}_{2} @ 26$ was determined to be $34.2^{38,39} \mathrm{kcal} / \mathrm{mol}$ from the Arrhenius plot of the rate constants obtained at 160 ${ }_{85} 190{ }^{\circ} \mathrm{C} .{ }^{38}$ It was also found that the release of a $\mathrm{H}_{2}$ molecule of $\mathrm{H}_{2} @ 27$ was almost three times faster than that of $\mathrm{H}_{2} @ \mathbf{2 6}$ and the activation energy was $32.4 \mathrm{kcal} / \mathrm{mol},{ }^{39}$ reflecting the slightly larger opening of $\mathrm{H}_{2} @ 27$. Recent investigations demonstrated that the rate of release of the encapsulated $\mathrm{H}_{2}$ 90 molecule can be well correlated to the opening size on the fullerene cage. $^{42}$

\subsection{Incorporation of a He atom}

Next, the insertion of the smallest noble-gas atom, ${ }^{3} \mathrm{He}$, within the fullerene cage of $\mathbf{2 6}$ was investigated at Yale University 95 by collaboration with Saunders and Cross. ${ }^{43}$ By heating an ODCB solution of 26 under ${ }^{3} \mathrm{He}$ gas $(20 \mathrm{~atm})$ at $80{ }^{\circ} \mathrm{C}$ for a few hours, ${ }^{3} \mathrm{He} @ 26$ at an occupation level of $0.1 \%$ was obtained. By monitoring the release of the ${ }^{3} \mathrm{He}$ atom from ${ }^{3} \mathrm{He} @ \mathbf{2 6}$, the activation energy for the release was determined 100 to be $22.8 \mathrm{kcal} / \mathrm{mol}$, which is lower than that for the release of a $\mathrm{H}_{2}$ molecule from $\mathrm{H}_{2} @ \mathbf{2 6} \mathbf{2}^{38,39}$ by $11.4 \mathrm{kcal} / \mathrm{mol}$. The release of a ${ }^{3} \mathrm{He}$ atom from ${ }^{3} \mathrm{He} @ 26$ can take place at near room temperature with the half-life of 40.3 hours at $30{ }^{\circ} \mathrm{C}$. Thus, it was required to develop a method to reduce the opening size 105 of ${ }^{3} \mathrm{He} @ 26$ in order to prevent the encapsulated He atom from escaping.

We found that, upon sodium borohydride reduction of a carbonyl group in 26, a transannular ether-forming reaction readily takes place at room temperature to give product $\mathbf{2 8}$ in $11086 \%$ yield. $^{44}$ The structure of $\mathbf{2 8}$ was confirmed by the X-ray crystallography. Theoretical calculations (B3LYP/6$31 \mathrm{G}^{* * / / B} 3 \mathrm{LYP} / 3-21 \mathrm{G}$ level) indicated that the activation 
energies for release of an encapsulated He atom from He@28 is $50.4 \mathrm{kcal} / \mathrm{mol}$, which is more than twice as large as that from $\mathrm{He} @ \mathbf{2 6},{ }^{38,39}$ indicating that effective reduction of the opening size of $\mathbf{2 6}$ has occurred.

Thus, we first conducted the insertion of a He atom within the cage of $\mathbf{2 6}$ under the conditions of $650 \mathrm{~atm}$ of $\mathrm{He}$ gas at $90{ }^{\circ} \mathrm{C}$ for 24 hours. Then, the resulting material was immediately subjected to the sodium borohydride reduction at -20 to $-25{ }^{\circ} \mathrm{C}$ to give desired product He@28 in $90 \%$ yield as 10 a stable complex. The occupation level of the He atom was $35 \%$ based on the mass spectroscopic analysis. ${ }^{44}$

Although the non-covalent interaction between the encapsulated He atom and the fullerene cage of $\mathbf{2 8}$ had been expected to be almost negligible, the NMR signal of the 15 methine proton of $\mathrm{He} @ \mathbf{2 8}$ showed a slight downfield shift by $0.36 \mathrm{~Hz}$ as compared to that of empty 28. The methine proton signal of $\mathrm{H}_{2} @ \mathbf{2 8}$, prepared separately, exhibited $1.9 \mathrm{~Hz}$ downfield shift relative to that of empty 28. These results demonstrate that the non-covalent interaction of the 20 encapsulated $\mathrm{H}_{2}$ molecule with the fullerene cage of $\mathbf{2 8}$ is larger than that of the encapsulated $\mathrm{He}$ atom and the NMR signal of the methine proton outside the cage is a good indicator of the electronic interaction inside the cage. ${ }^{44}$

\subsection{Incorporation of two $\mathrm{H}_{2}$ molecules into an open-cage $\mathrm{C}_{70}$}

${ }_{25}$ Taking the thickness of $\pi$-electron cloud of fullerenes into consideration, the size of the inner cavity of $\mathrm{C}_{70}$ is estimated to be $4.6 \AA$ along the long axis and $3.6 \AA$ along the short axis, which is larger than that of $\mathrm{C}_{60}$ (3.6 $\AA$ in inner diameter). Therefore, it is expected to be possible to insert more than one 30 small molecule ${ }^{45}$ through a newly created opening on the surface of $\mathrm{C}_{70}$. However, most studies on this line have previously been made only on $\mathrm{C}_{60}$ because of the wealth of knowledge about the chemical reactivity of $\mathrm{C}_{60}$ and also due to its higher symmetry. Thus, we challenged to prepare open35 cage $\mathrm{C}_{70}$ derivative $\mathbf{2 9}^{46}$ with a 13 -membered-ring opening by applying similar procedures to those used for the synthesis of the $\mathrm{C}_{60}$ analogue $26 .{ }^{25}$ A thermal reaction of $\mathrm{C}_{70}$ with 3,6di(2-pyridyl)pyridazine in refluxing 1-chloronaphthalene gave eight-membered-ring compound 30 (40\%), and subsequent 40 oxidation with singlet oxygen afforded 12-membered-ring compound $31(49 \%)$. Then, the opening of $\mathbf{3 1}$ was enlarged by insertion of a sulfur atom to the rim of the opening using TDAE as a $\pi$-electron donor to give 29 (94\%). The results of the X-ray crystallography of $\mathbf{2 9}$ showed that the opening size 45 of $\mathbf{2 9}$ is almost the same as that of $\mathrm{C}_{60}$ analogue $\mathbf{2 6}{ }^{25}$

The insertion of $\mathrm{H}_{2}$ molecule(s) was carried out by applying $890 \mathrm{~atm}$ of $\mathrm{H}_{2}$ gas at $230{ }^{\circ} \mathrm{C}$ for 8 hours. The successful encapsulation of molecular hydrogen was clearly demonstrated by appearance of a new intense signal in the ${ }^{1} \mathrm{H}$ ${ }_{50} \mathrm{NMR}$ spectrum at unusually high field, $\delta=-16.51 \mathrm{ppm}$ in ODCB- $d_{4}$. This signal was assigned to the resonance of $\mathrm{H}_{2} @ 29$ based on the mass spectroscopic data. Noteworthy is that a small signal was also observed at $\delta=-15.22 \mathrm{ppm}$. Upon low-temperature NMR studies, this signal completely

${ }_{55}$ disappeared by cooling the solution to $-60{ }^{\circ} \mathrm{C}$ and reappeared as two new signals at $-80{ }^{\circ} \mathrm{C}$, which became sharp at $-100{ }^{\circ} \mathrm{C}$ with the chemical shift of $\delta=-12.87 \mathrm{ppm}$ and $-17.38 \mathrm{ppm}$.
The observed dynamic behavior is interpreted by assuming the positional exchange of two $\mathrm{H}_{2}$ molecules encapsulated in 60 open-cage 29, i.e., $\left(\mathrm{H}_{2}\right)_{2} @ 29$. The line-shape analysis of the low-temperature NMR spectra gave $E_{\mathrm{a}}=8.0 \mathrm{kcal} / \mathrm{mol}$ for this positional exchange. The yield of $\mathrm{H}_{2} @ 29$ and $\left(\mathrm{H}_{2}\right)_{2} @ 29$ was $97 \%$ and $3 \%$, respectively, as estimated from the integrated areas of the NMR signals.

${ }_{65}$ In accord with the results of the X-ray crystallography, i.e., the opening of 29 being almost the same size as that of $\mathbf{2 6}$, the rate for the release of a $\mathrm{H}_{2}$ molecule from $\mathrm{H}_{2} @ 29$, monitored at temperaures above $160{ }^{\circ} \mathrm{C}$, was almost as fast as that from the $\mathrm{C}_{60}$ analogue $\mathrm{H}_{2} @ 26 .^{25}$ The activation energy was 70 determined to be $33.8 \mathrm{kcal} / \mathrm{mol}$.

\subsection{Closure of the opening}

As described above, we have succeeded in introducing a $\mathrm{H}_{2}$ molecule into the carbonaceous cage of $\mathbf{2 6}$ at the occupation level of $100 \%{ }^{38}$ Subsequently, we developed a method to 75 "suture" the 13-membered-ring opening of $\mathrm{H}_{2} @ 26$ to complete the molecular surgery operation. ${ }^{47-51}$ Prior to this study, there had been no report for the attempt at suturing a once formed opening on the fullerene cage.

Apparently, the first step for the size-reduction of the 1380 membered-ring in $\mathrm{H}_{2} @ \mathbf{2 6}$ should be the removal of the sulfur atom. We first conducted an oxidation of the sulfide unit of $\mathrm{H}_{2} @ 26$ by $m$-chloroperbenzoic acid in order to make the sulfur atom readily removable. The reaction proceeded at room temperature to give sulfoxide derivative $\mathrm{H}_{2} @ 32$ almost ${ }_{85}$ quantitatively. Then, irradiation of a solution of $\mathrm{H}_{2} @ 32$ in benzene with visible light at room temperature caused the elimination of the SO unit to give product $\mathrm{H}_{2} @ 12$ having a 12 -membered-ring opening in $42 \%$ yield. The encapsulated $\mathrm{H}_{2}$ molecule was completely retained throughout these two 90 steps because the two reactions were conducted at room temperature. $^{38}$ This removal of a sulfur atom made the distance between two carbonyl carbons across the opening closer from $3.89 \AA$ for $\mathrm{H}_{2} @ \mathbf{2 6}$ to $3.12 \AA$ for $\mathrm{H}_{2} @ \mathbf{1 2}$ as shown by calculations (B3LYP/6-31G* level). The reductive 95 coupling of the two carbonyl groups efficiently proceeded by McMurry reaction using $\mathrm{Ti}(0)^{52}$ at $80{ }^{\circ} \mathrm{C}$ to give product $\mathrm{H}_{2} @ 10$ with an eight-membered-ring opening in $88 \%$ yield. Here, it is to be noted that the MALDI-TOF mass spectrum of $\mathrm{H}_{2} @ 10$ already exhibited an intense peak of $\mathrm{H}_{2} @ \mathrm{C}_{60}$ together 100 with a smaller molecular ion peak of $\mathrm{H}_{2} @ \mathbf{1 0}$.

The final step to remove all the remaining organic addends on the $\mathrm{C}_{60}$ cage was performed by simply heating a powder of $\mathrm{H}_{2} @ 10(245 \mathrm{mg})$ in a vacuum-sealed tube placed in an electric furnace at $340{ }^{\circ} \mathrm{C}$ for 2 hours. Separation of the 105 reaction mixture was carried out by flash column chromatography over silica gel eluted with carbon disulfide to afford a purple solution containing desired $\mathrm{H}_{2} @ \mathrm{C}_{60}(118 \mathrm{mg}$, $67 \%$ yield), contaminated by $9 \%$ of empty $\mathrm{C}_{60}$. Subsequently, complete separation of $\mathrm{H}_{2} @ \mathrm{C}_{60}$ from empty $\mathrm{C}_{60}$ was achieved 10 by recycling HPLC on semipreparative Cosmosil Buckyprep columns (two directly connected columns; $250 \mathrm{~mm}$ length, 10 $\mathrm{mm}$ i.d.; mobile phase, toluene; flow rate, $4 \mathrm{~mL} / \mathrm{min}$ ) to give $\mathrm{H}_{2} @ \mathrm{C}_{60}$ as a pure material after 20 recycles (total retention time, 399 minutes; the retention time for empty $\mathrm{C}_{60}, 395$ 
minutes). The adsorption mechanism of the Buckyprep column is largely based on the $\pi-\pi$ interaction with pyrenyl groups in the stationary phase. A very weak van der Waals interaction between the encapsulated $\mathrm{H}_{2}$ molecule and the $\mathrm{C}_{60}$ $5 \pi$-system must have contributed to this separation.

The ${ }^{13} \mathrm{C}$ NMR spectrum of pure $\mathrm{H}_{2} @ \mathrm{C}_{60}$ exhibited a signal at $\delta=142.844 \mathrm{ppm}$ in ODCB- $d_{4}$, which is very slightly downfield shifted by $0.078 \mathrm{ppm}$ relative to that of empty $\mathrm{C}_{60}$. The ${ }^{1} \mathrm{H}$ NMR signal of the encapsulated $\mathrm{H}_{2}$ molecule appeared 10 at $\delta=-1.44 \mathrm{ppm}$ in ODCB- $d_{4}$, which is $5.98 \mathrm{ppm}$ upfield shifted from dissolved free $\mathrm{H}_{2}$ molecule. This value is comparable to the $6.36 \mathrm{ppm}$ upfield shift of a ${ }^{3} \mathrm{He}$ NMR signal for ${ }^{3} \mathrm{He} @ \mathrm{C}_{60}$, suggesting that this nearly 6 ppm upfield shift is a universal value corresponding to the magnetic field at the 15 central position in the $\mathrm{C}_{60}$ core. The IR spectrum of $\mathrm{H}_{2} @ \mathrm{C}_{60}$ was almost the same as that of empty $\mathrm{C}_{60}$, exhibiting four absorption bands at $1429.2,1182.3,576.7$, and $526.5 \mathrm{~cm}^{-1}$ (to be compared with $1429.2,1182.3,575.7$, and $526.5 \mathrm{~cm}^{-1}$ for empty $\mathrm{C}_{60}$ ). Only the band at $576.7 \mathrm{~cm}^{-1}$ of $\mathrm{H}_{2} @ \mathrm{C}_{60}$, 20 corresponding to an out-of-plane vibration mode, ${ }^{53}$ is higher in energy than that of $\mathrm{C}_{60}$ by $1.0 \mathrm{~cm}^{-1}$. This might be interpreted as evidence of a very slight repulsive interaction between the $\mathrm{C}_{60}$ cage and the inner $\mathrm{H}_{2}$ molecule. The UV-vis spectrum of $\mathrm{H}_{2} @ \mathrm{C}_{60}$ was almost the same as that of $\mathrm{C}_{60}$.

25 The cyclic voltammetry and differential pulse voltammetry of $\mathrm{H}_{2} @ \mathrm{C}_{60}$ at room temperature exhibited three reversible reduction waves at $E_{1 / 2}-1.13,-1.54$, and $-1.99 \mathrm{~V}$ vs $\mathrm{Fc} / \mathrm{Fc}^{+}$in ODCB and one irreversible oxidation peak at $E_{\mathrm{pa}}$ $+1.62 \mathrm{~V}$ in TCE, which were virtually the same as those of 30 empty $\mathrm{C}_{60}$. However, when more negative potential was applied using the solution in toluene-acetonitrile (5.4:1) under vacuum at $-10{ }^{\circ} \mathrm{C},{ }^{54}$ the fourth, fifth, and sixth reduction waves became observable, which were found to be more cathodic than the reduction of empty $\mathrm{C}_{60}$ by $0.04,0.07$,

35 and $0.15 \mathrm{~V}$, suggesting that $\mathrm{H}_{2} @ \mathrm{C}_{60}$ becomes more difficult to be reduced as it acquires more than three electrons. ${ }^{49}$

$\mathrm{H}_{2} @ \mathrm{C}_{60}$ is thermally stable. Upon heating $\mathrm{H}_{2} @ \mathrm{C}_{60}$ at $500{ }^{\circ} \mathrm{C}$ for 10 minutes under vacuum, no decomposition or no release of encapsulated $\mathrm{H}_{2}$ molecule was observed at all.

\section{4. Organic derivatization of $\mathrm{H}_{2} @ \mathrm{C}_{60}$}

In order to examine the effect of encapsulated $\mathrm{H}_{2}$ molecule on the reactivity of the outer $\mathrm{C}_{60}$ cage, the solid-state mechanochemical dimerization of $\mathrm{H}_{2} @ \mathrm{C}_{60}$ (occupation level of $91 \%$ ) was conducted under the same conditions ${ }^{55}$ reported ${ }_{45}$ previously. The dumbbell-shaped dimer, $\left(\mathrm{H}_{2} @ \mathrm{C}_{60}\right)_{2},{ }^{47}$ was obtained in $30 \%$ isolated yield similarly to the reaction of empty $\mathrm{C}_{60}$. Apparently the inside hydrogen does not affect the reactivity of the $\mathrm{C}_{60}$ cage. The NMR signal for the inside $\mathrm{H}_{2}$ molecule was observed as a singlet at $\delta=-4.04 \mathrm{ppm}$, which is ${ }_{50} 8.58 \mathrm{ppm}$ upfield shifted from that of free $\mathrm{H}_{2}$ similarly to the case for ${ }^{3} \mathrm{He} @ \mathrm{C}_{120}{ }^{56}$ (8.81 ppm upfield shift from the signal of free $\left.{ }^{3} \mathrm{He}\right)$. Three additional fullerene derivatives $\mathrm{H}_{2} @ 33$, $\mathrm{H}_{2} @ 34$, and $\mathrm{H}_{2} @ 35$ were also synthesized and their NMR signals for the encapsulated $\mathrm{H}_{2}$ molecule in ODCB- $d_{4}$ ${ }_{55}$ appeared at $\delta=-3.27,-4.30$, and $-4.64 \mathrm{ppm}$, respectively. ${ }^{49}$ Since the values of chemical shift change sensitively according to the difference in structures of the organic addends, the encapsulated $\mathrm{H}_{2}$ molecule within $\mathrm{C}_{60}$ cage can also be used as a good probe to investigate the chemical 60 reactions at the exterior of the cage, just as the ${ }^{3} \mathrm{He}$ atom inside $\mathrm{C}_{60}$ (occupation level of $0.1 \%$ ) has been used for this purpose. $^{15}$

Furthermore, several organic and organometallic derivatives of $\mathrm{H}_{2} @ \mathrm{C}_{60}$ were prepared at the University of ${ }_{65}$ Tokyo by the group of Nakamura. ${ }^{57}$ The NMR signals for the encapsulated $\mathrm{H}_{2}$ molecule appeared at $\delta=-10.39 \mathrm{ppm}$ for compound $\mathrm{H}_{2} @ 36$ in $\mathrm{CDCl}_{3}-\mathrm{CS}_{2}, \delta=-9.79 \mathrm{ppm}$ for potassium cyclopentadienide $\mathrm{H}_{2} @ 37$ in THF- $d_{8}, \delta=-10.44$ ppm for bucky ferrocene $\mathrm{H}_{2} @ 38$ in $\mathrm{CDCl}_{3}-\mathrm{CS}_{2}$, and $\delta=-$ $7010.77 \mathrm{ppm}$ for tetraaminofullerene epoxide $\mathrm{H}_{2} @ 39 \mathbf{3}$ in $\mathrm{CDCl}_{3}$. Although the ${ }^{1} \mathrm{H}$ NMR chemical shifts for the encapsulated $\mathrm{H}_{2}$ molecule of amphiphilic derivative $\mathrm{H}_{2} @ 3$ 39b were measured in a variety of solvents, such as THF- $d_{8}$, DMSO- $d_{6}$-toluene- $d_{8}$ $(1: 1)$, DMSO- $d_{6}$, and $\mathrm{D}_{2} \mathrm{O}-\mathrm{DMSO}-d_{6}(1: 1)$, no specific 75 solvent effect on the chemical shift was observed.

\section{Utilization of the encapsulated $\mathrm{H}_{2}$ molecule as an NMR probe}

Saunders reported that the ${ }^{3} \mathrm{He}$ NMR signal of hexaanion ${ }^{3} \mathrm{He} @ \mathrm{C}_{60}{ }^{6-}$ appeared at dramatically high field $(\delta=-48.7 \mathrm{ppm}$ 80 relative to the signal of free ${ }^{3} \mathrm{He}$ ), reflecting the strong shielding effect of $\mathrm{C}_{60}{ }^{6-} \cdot{ }^{13}$ This was apparently due to the high aromaticity of $\mathrm{C}_{60}{ }^{6-}$. Theoretical as well as experimental studies indicated that all of the hexagons and pentagons of $\mathrm{C}_{60}{ }^{6-}$ showed diamagnetic ring currents. Among the other ${ }_{85}$ possible anionic states of $\mathrm{C}_{60}$, dianion $\mathrm{C}_{60}{ }^{2-}$ is particularly important in synthetic chemistry for introduction of two functional groups on the $\mathrm{C}_{60}$ cage. ${ }^{58}$ Although the " $2(N+1)^{2}$ rule", ${ }^{59}$ describing the spherical aromaticity of $I_{\mathrm{h}}$-symmetrical fullerenes, proposed by Hirsh, predicts that the $62-\pi$-electron 90 system should not have high aromaticity, little had been known about the aromaticity of $\mathrm{C}_{60}{ }^{2-}$ prior to our study. ${ }^{60}$

Thus, we carried out the generation of $\mathrm{H}_{2} @ \mathrm{C}_{60}{ }^{2-}$ by using $\mathrm{CH}_{3} \mathrm{SNa}^{61}$ as a reductant in $\mathrm{CD}_{3} \mathrm{CN}$ under vacuum. The ${ }^{1} \mathrm{H}$ NMR signal of the encapsulated $\mathrm{H}_{2}$ molecule of $\mathrm{H}_{2} @ \mathrm{C}_{60}{ }^{2-}$ 95 was observed at surprisingly low field such as $\delta=26.36 \mathrm{ppm}$. This is downfield shifted by $27.8 \mathrm{ppm}$ relative to that of neutral $\mathrm{H}_{2} @ \mathrm{C}_{60}\left(\delta=-1.44 \mathrm{ppm}\right.$ in ODCB- $\left.d_{4}\right){ }^{47}$ This result demonstrates that the overall aromaticity within the cage of $\mathrm{C}_{60}$ decreases drastically upon two-electron reduction. The 100 NICS (nucleus independent chemical shifts) ${ }^{62}$ calculations (B3LYP/6-31G* level) for all the hexagons and pentagons of $\mathrm{C}_{60}{ }^{2-}$ suggested that, upon two-electron reduction, the ring currents of all hexagons become paramagnetic while those of all pentagons become diamagnetic. Because there exist more 105 hexagons than pentagons in $\mathrm{C}_{60}$, the antiaromatic character of hexagons overwhelms the aromatic character of pentagons, resulting in the strong deshielding effect inside the cage. This is the first time that the reversal of aromaticity/antiaromaticity for hexagons and pentagons of fullerenes was observed.

The similar reversal was observed even for the dianion of heavily functionalized $\mathrm{C}_{60}$ such as open-cage fullerene $\mathrm{H}_{2} @ 26$. The NMR signal of $\mathrm{H}_{2} @ \mathbf{2 6}^{2-}$ was observed at $\delta=8.10$ ppm in $\mathrm{CD}_{3} \mathrm{CN}$, which is downfield shifted by $15.4 \mathrm{ppm}$ relative to that of neutral $\mathrm{H}_{2} @ 26\left(\delta=-7.25\right.$ ppm in ODCB- $\left.d_{4}\right){ }^{38}$ The 
NICS calculations (B3LYP/6-31G* level) showed that the aromatic and antiaromatic characters of hexagons and pentagons are mostly reversed in the same way as those for $\mathrm{H}_{2} @ \mathrm{C}_{60}{ }^{2-}$, in spite of the highly ruptured $\pi$-system in $\mathrm{H}_{2} @ 26$.

While the aromaticity of the spherically conjugated system of $\mathrm{C}_{60}$ is proved to be drastically changed when $\mathrm{C}_{60}$ acquired extra electrons, ${ }^{13,60}$ the research on the magnetic properties of ionic fullerenes are still quite limited. Thus, we prepared dichloromethyl- $\mathrm{C}_{60}$ cation ${ }^{63}$ and (1-octynyl)- $\mathrm{C}_{60}$ anion ${ }^{64}$

10 encapsulating a $\mathrm{H}_{2}$ molecule $\left(\mathrm{H}_{2} @ \mathbf{4 0}^{+}\right.$and $\left.\mathrm{H}_{2} @ \mathbf{4 1 ^ { - }}\right),{ }^{65}$ as these compounds appeared to be well suited for the study of the difference in aromaticity between the monofunctionalized $\mathrm{C}_{60}$ cation and anion. The cation $\mathrm{H}_{2} @ \mathbf{4 0}^{+}$was generated in $\mathrm{CF}_{3} \mathrm{SO}_{3} \mathrm{H}$ as a stable species and the NMR signal of the 15 encapsulated $\mathrm{H}_{2}$ molecule was observed at $\delta=-2.89 \mathrm{ppm}$. The signal was downfield shifted by $1.73 \mathrm{ppm}$ from a $\mathrm{H}_{2}$ signal of the corresponding neutral compound $\mathrm{H}_{2} @ \mathbf{4 2}(\delta=$ $-4.62 \mathrm{ppm}$ in $\left.\mathrm{CS}_{2}-\mathrm{CDCl}_{3}(1: 1)\right)$, indicating that the aromaticity of $\mathbf{4 0}^{+}$was slightly decreased as compared to that 20 of 42. On the other hand, an NMR signal for the encapsulated $\mathrm{H}_{2}$ molecule of anion $\mathrm{H}_{2} @ \mathbf{4 1}^{-}$, which was also generated as a stable species in THF- $d_{8}$, appeared at $\delta=-0.60 \mathrm{ppm}$. This resonance was shifted to lower field than that for a $\mathrm{H}_{2}$ molecule of neutral counterpart $\mathrm{H}_{2} @ \mathbf{4 3}(\delta=-4.75$ ppm in $\left.{ }_{25} \mathrm{CS}_{2}-\mathrm{CDCl}_{3}(1: 1)\right)$, again indicating the decrease in aromaticity. The relatively small difference in the chemical shifts of the encapsulated $\mathrm{H}_{2}$ molecule between $\mathrm{H}_{2} @ \mathbf{4 0}^{+}$and $\mathrm{H}_{2} @ \mathbf{4 1}^{-}$ (absolute $\Delta \delta$ value, $2.29 \mathrm{ppm}$ ) demonstrates that the aromaticity of the fullerenes are affected to a comparative 30 degree in these cationic and anionic systems.

\section{Physical properties of the $\mathrm{H}_{2}$ molecule inside $\mathrm{C}_{60}$}

The encapsulated $\mathrm{H}_{2}$ molecule in $\mathrm{H}_{2} @ 26$ is isolated from the outside environment by the surrounding fullerene cage 35 because the opening is so small that only a $\mathrm{He}$ atom or a $\mathrm{H}_{2}$ molecule can go through. Actually, the nuclear spin-lattice relaxation time $\left(T_{1}\right)$ of the encapsulated $\mathrm{H}_{2}$ of $\mathrm{H}_{2} @ 26$ upon the ${ }^{1} \mathrm{H}$ NMR measurements were not affected by the presence of molecular oxygen as a paramagnetic species in the ${ }_{40}$ solution. ${ }^{38}$ The $T_{1}$ values of the encapsulated $\mathrm{H}_{2}$ molecule and one of the pyridyl proton of $\mathrm{H}_{2} @ 26$ in ODCB- $d_{4}$ are $0.2 \mathrm{~s}$ and $3.9 \mathrm{~s}$ under vacuum and 0.2 and $0.9 \mathrm{~s}$ in an oxygen-saturated solution, respectively. In $\mathrm{H}_{2} @ \mathrm{C}_{60}$, synthesized by complete restoration of the opening of $\mathrm{H}_{2} @ \mathbf{2 6}$, the encapsulated $\mathrm{H}_{2}$ is 45 completely isolated from the outside. As judged from the difference in chemical shift of ${ }^{13} \mathrm{C}$ NMR $(\Delta \delta=0.078 \mathrm{ppm}$; vide supra), the interaction of the encapsulated $\mathrm{H}_{2}$ and the outer $\mathrm{C}_{60}$ cage in $\mathrm{H}_{2} @ \mathrm{C}_{60}$ appears to exist but should be very weak.

50 To investigate the nature of such interaction, the $T_{1}$ values of $\mathrm{H}_{2}$ molecule encapsulated in $\mathrm{C}_{60}$ cage as well as those of free $\mathrm{H}_{2}$ molecule were measured in Columbia University by the group of Turro for the first time. ${ }^{66}$ The $T_{1}$ values of free $\mathrm{H}_{2}$ at $300 \mathrm{~K}$ were found to depend significantly on the organic 55 solvent, for example, from $1.44 \mathrm{~s}$ (benzene) to $0.84 \mathrm{~s}\left(\mathrm{CCl}_{4}\right)$. A somewhat larger variation of $T_{1}$ values was observed for $\mathrm{H}_{2} @ \mathrm{C}_{60}$ : from $0.118 \mathrm{~s}$ (benzene) to $0.046 \mathrm{~s}\left(\mathrm{CCl}_{4}\right)$, which are
12-18 times smaller than those for free $\mathrm{H}_{2}$. However, the value of $T_{1}$ for both $\mathrm{H}_{2}$ and $\mathrm{H}_{2} @ \mathrm{C}_{60}$ does not significantly ${ }_{60}$ change between the solutions in benzene- $h_{6}$ and benzene- $d_{6}$. Therefore, the dominating interactions determining $\mathrm{H}_{2}$ and $\mathrm{H}_{2} @ \mathrm{C}_{60}$ nuclear relaxation are concluded to be intramolecular. On the other hand, the $T_{1}$ value for both $\mathrm{H}_{2}$ and $\mathrm{H}_{2} @ \mathrm{C}_{60}$ was found to be temperature dependent with the maximum value ${ }_{65}$ observed at $\sim 240 \mathrm{~K}$. This kind of temperature dependence of $T_{1}$ is consistent with two different relaxation mechanisms dominantly operaing at different temperature ranges, that is, below and above $240 \mathrm{~K}$, for both $\mathrm{H}_{2}$ and $\mathrm{H}_{2} @ \mathrm{C}_{60}$. Qualitatively, the dipole-dipole interaction accounts for the 70 observed increase in $T_{1}$ with temperature below $240 \mathrm{~K}$, whereas the spin-rotation interaction accounts for the observed decrease in $T_{1}$ with temperature above $240 \mathrm{~K}$. These facts and consideration derived therefrom imply that the $\mathrm{H}_{2}$ in both environments rotates through large angles between 75 collisions with the solvent shell or with the walls of the $C_{60}$ cage.

Although the encapsulated $\mathrm{H}_{2}$ molecule in $\mathrm{C}_{60}$ is completely isolated from the outside, it can communicate with the outside world. ${ }^{67}$ First, no differences in the triplet life 80 times were observed for $\mathrm{C}_{60}, \mathrm{H}_{2} @ \mathrm{C}_{60}$, and $\mathrm{D}_{2} @ \mathrm{C}_{60}$ upon irradiation of laser pulse. Thus, the interaction of encapsulated $\mathrm{H}_{2}$ and $\mathrm{D}_{2}$ with the paramagnetic walls of the triplet fullerene is too weak to be determined by triplet lifetime measurements. However, clear differences in 85 reactivity were observed for the quenching of singlet oxygen ${ }^{1} \mathrm{O}_{2}$ by $\mathrm{C}_{60}, \mathrm{H}_{2} @ \mathrm{C}_{60}$, and $\mathrm{D}_{2} @ \mathrm{C}_{60}$. The absolute quenching rate constants $k_{\mathrm{q}}$ of ${ }^{1} \mathrm{O}_{2}$ by $\mathrm{H}_{2} @ \mathrm{C}_{60}, \mathrm{D}_{2} @ \mathrm{C}_{60}$, and $\mathrm{C}_{60}$ were determined using a time-resolved method in $\mathrm{CS}_{2}$ to give the values of $k_{\mathrm{q}}\left(\mathrm{H}_{2} @ \mathrm{C}_{60}\right)=1.5 \times 10^{5} \mathrm{M}^{-1} \mathrm{~s}^{-1}, k_{\mathrm{q}}\left(\mathrm{D}_{2} @ \mathrm{C}_{60}\right)=0.49$ $90 \times 10^{5} \mathrm{M}^{-1} \mathrm{~s}^{-1}$, and $k_{\mathrm{q}}\left(\mathrm{C}_{60}\right)=0.38 \times 10^{5} \mathrm{M}^{-1} \mathrm{~s}^{-1}$, respectively. The results demonstrate that both $\mathrm{H}_{2} @ \mathrm{C}_{60}$ and $\mathrm{D}_{2} @ \mathrm{C}_{60}$ are better quenchers than empty $\mathrm{C}_{60}$. Importantly, the ${ }^{1} \mathrm{O}_{2}$ can sense the difference between encapsulated $\mathrm{H}_{2}$ and $\mathrm{D}_{2}$. The rate constants for quenching of ${ }^{1} \mathrm{O}_{2}$ by free $\mathrm{H}_{2}$ and $\mathrm{D}_{2}$ in $\mathrm{CCl}_{4}$ 95 were also measured to afford the values of $k_{\mathrm{q}}\left(\mathrm{H}_{2}\right)=0.81 \times 10^{5}$ $\mathrm{M}^{-1} \mathrm{~s}^{-1}, k_{\mathrm{q}}\left(\mathrm{D}_{2}\right)=0.024 \times 10^{5} \mathrm{M}^{-1} \mathrm{~s}^{-1}$, which are significantly smaller than the values by $\mathrm{H}_{2} @ \mathrm{C}_{60}$ and $\mathrm{D}_{2} @ \mathrm{C}_{60}$. This is a unique example of an encapsulated guest having a significantly larger rate constant for quenching than the free 100 guest. Since ${ }^{1} \mathrm{O}_{2}$ might form an exciplexes with the outer surface of fullerenes, it is speculated that this unique behavior can be attributed to a significant life time to provide an opportunity for ${ }^{1} \mathrm{O}_{2}$ and the encapsulated $\mathrm{H}_{2}$ to interact for a condiderable period of time.

105 Interaction of the encapsulated $\mathrm{H}_{2}$ molecule with another species outside the fullerene cage is also seen for the interaction with nitroxide radicals. In the presence of paramagnet nitroxide radicals, bimolecular contribution to the spin-lattice relaxation rate, $1 / T_{1}$, for the protons of $\mathrm{H}_{2}$ and ${ }_{110} \mathrm{H}_{2} @ \mathrm{C}_{60}$ dissolved in toluene- $d_{8}$ were investigated. ${ }^{68}$ The measured relaxation rates depended on the concentration of the nitroxide, $[S]$, according to the relationship: $1 / T_{1}=1 / T_{1,0}+$ $R_{1}[S]$, where $T_{1,0}$ is the relaxation time in the absence of paramagnetic relaxant and $R_{1}\left(\mathrm{M}^{-1} \mathrm{~s}^{-1}\right)$ is the second-order 115 relaxation coefficiant, or relaxibity. It was found that the 
relaxation effect of the paramagnets is enhanced 5-fold in $\mathrm{H}_{2} @ \mathrm{C}_{60}$ compared to free $\mathrm{H}_{2}$ under the same conditions.

\section{Concluding remarks}

In this article we have outlined recent progress toward 5 synthesizing endohedral fullerenes not by a physical method but by the stepwise transformations of fullerenes by organic reactions. This molecular surgical operation was shown to be effective for realization of a new endohedral fullerene, $\mathrm{H}_{2} @ \mathrm{C}_{60}$. This method can be applied to the preparation of 10 endohedral fullerenes encapsulating gas atoms or molecules with sizes comparable or smaller than a $\mathrm{H}_{2}$ molecule. While the preparation of bowl-shaped compounds by the wide incision of a $\mathrm{C}_{60}$ cage provided access to the encapsulation of molecules larger than $\mathrm{H}_{2}$, i.e., $\mathrm{H}_{2} \mathrm{O}$ and $\mathrm{CO}$, the operation to 15 suture the opening must be a highly difficult task. Of course the most important and ultimate goal of the present method would be to develop a route to the encapsulation of metal atoms affording endohedral metallofullerenes. However, as far as the present method is used, the insertion of metal ions 20 such as $\mathrm{Li}^{+}$and $\mathrm{Na}^{+}$through the opening is difficult because of their strong coordination with two carbonyl oxygen atoms at the opening. Further development of the technique for the chemical transformations of the fullerene cage will be crucial for this project to be accomplished.

\section{Notes and references}

1 Endofullerenes: A New Family of Carbon Clusters, eds. T. Akasaka, S. Nagase, Kluwer Academic Publisher, Dordrecht, The Netherlands, 2002.

302 Fullerenes: Chemistry, Physics and Technology, eds. K. M. Kadish, R. S. Ruoff, John Wiley \& Sons, New York, 2000, pp 357-393.

3 D. S. Bethune, R. D. Johnson, J. R. Salem, M. S. de Vries, C. S. Yannoni, Nature, 1993, 366, 123; S. Nagase, K. Kobayashi, T. Akasaka, Bull. Chem. Soc. Jpn., 1996, 69, 2131; H. Shinohara, Rep.

35 Prog. Phys., 2000, 63, 843; S. Liu, S. Sun, J. Organomet. Chem., 2000, 599, 74 .

4 T. Suzuki, Y. Maruyama, T. Kato, K. Kikuchi, Y. Achiba, J. Am. Chem. Soc., 1993, 115, 11006.

5 S. Nagase, K. Kobayashi, J. Chem. Soc., Chem. Commun., 1994, 1837; S. Nagase, K. Kobayashi, Chem. Phys. Lett., 1994, 228, 106.

6 For review, see: L. Dunsch, S. Yang, Small, 2007, 3, 1298.

7 J. R. Pinzón, M. E. Plonska-Brzezinska, C. M. Cardona, A. J. Athans, S. S. Gayathri, D. M. Guldi, M. Á. Herranz, N. Martin, T. Torres, L. Echegoyen. Angew. Chem. Int. Ed., 2008, 47, 4173.

458 M. Mikawa, H. Kato, M. Okumura, M. Narazaki, Y. Kanazawa, N. Miwa, H. Shinohara, Bioconjugate Chem., 2001, 12, 510; R. D. Bolskar, A. F. Benedetto, L. O. Husebo, R. E. Price, E. F. Jackson, S. Wallace, L. J. Wilson, J. M. Alford, J. Am. Chem. Soc., 2003, 125, 5471; É. Tóth, R. D. Bolskar, A. Borel, G. González, L. Helm, A. E. Merbach, B. Sitharaman, L. J. Wilson, J. Am. Chem. Soc., 2005, 127, 799; C.-Y. Shu, L.-H. Gan, C.-R. Wang, X.-1. Pei, H.-b. Han, Carbon, 2006, 44, 496; S. Laus, B. Sitharaman, É. Tóth, R. D. Bolskar, L. Helm, L. J. Wilson, A. E. Merbach, J. Phys. Chem. C, 2007, 111, 5633.

${ }_{55} 9$ S.-i. Kobayashi, S. Mori, S. Iida, H. Ando, T. Takenobu, Y. Taguchi, A. Fujiwara, A. Taninaka, H. Shinohara, Y. Iwasa, J. Am. Chem. Soc., 2003, 125, 8116

10 T. Tsuchiya, R. Kumashiro, K. Tanigaki, Y. Matsunaga, M. O. Ishitsuka, T. Wakahara, Y. Maeda, Y. Takano, M. Aoyagi, T.

60 Akasaka, M. T. H. Liu, T. Kato, K. Suenaga, J. S. Jeong, S. Iijima, F. Kimura, T. Kimura, S. Nagase, J. Am. Chem. Soc., 2008, 130, 450.

11 M. Saunders, H. A. Jiménez-Vázquez, R. J. Cross, R. J. Poreda, Science, 1993, 259, 1428; M. Saunders, H. A. Jiménez-Vázquez, R. J.
Cross, S. Mroczkowski, D. I. Freedberg, F. A. L. Anet, Nature, 1994, 367, 256; M. Saunders, H. A. Jiménez-Vázquez, R. J. Cross, J. Am. Chem. Soc., 1994, 116, 2193; M. Saunders, R. J. Cross, H. A. Jiménez-Vázquez, R. Shimshi, A. Khong, Science, 1996, 271, 1693.

12 This occupaation level can be increased to $1 \%$ when $\mathrm{C}_{60}$ is pre-treated with $\mathrm{KCN}$, though the reason is not well understood: R. J. Cross, A. Khong, M. Saunders, J. Org. Chem., 2003, 68, 8281.

13 E. Shabtai, A. Weitz, R. C. Haddon, R. E. Hoffman, M. Rabinovitz, A. Khong, R. J. Cross, M. Saunders, P.-C. Cheng, L. T. Scott, J. Am. Chem. Soc., 1998, 120, 6389.

14 M. Saunders, H. A. Jiménez-Vázquez, R. J. Cross, W. E. Billups, C. Gesenberg, A. Gonzalez, W. Luo, R. C. Haddon, F. Diederich, A. Herrmann, J. Am. Chem. Soc., 1995, 117, 9305; A.; P. R. Birkett, M. Bühl, A. Khong, M. Saunders, R. Taylor, J. Chem. Soc., Perkin Trans. 2, 1999, 2037; T. Sternfeld, R. E. Hoffman, M. Saunders, R. J. Cross, M. S. Syamala, M. Rabinovitz, J. Am. Chem. Soc., 2002, 124, 8786; 80 T. Sternfeld, M. Saunders, R. J. Cross, M. Rabinovitz, Angew. Chem., Int. Ed., 2003, 42, 3136.

15 For exapmle, see: M. Saunders, H. A. Jiménez-Vázquez, B. W. Bangerter, R. J. Cross, J. Am. Chem. Soc., 1994, 116, 3621; D. I. Schuster, J. Cao, N. Kaprinidis, Y. Wu, A. W. Jensen, Q. Lu, H. Wang, S. R. Wilson, J. Am. Chem. Soc., 1996, 118, 5639; R. J. Cross, H. A. Jiménez-Vázquez, Q. Lu, M. Saunders, D. I. Schuster, S. R. Wilson, H. Zhao, J. Am. Chem. Soc., 1996, 118, 11454; M. Rüttimann, R. F. Haldimann, L. Isaacs, F. Diederich, A. Khong, H. A. Jiménez-Vázquez, R. J. Cross, M. Saunders, Chem. Eur. J., 1997, 3,

90 1071; G.-W. Wang, M. Saunders, R. J. Cross, J. Am. Chem. Soc., 2001, 123, 256.

16 M. Frunzi, R. J. Cross, M. Saunders, J. Am. Chem. Soc., 2007, 129, 13343.

17 B. A. DiCamillo, R. L. Hettich, G. Guiochon, R. N. Compton, M. Saunders, H. A. Jiménez-Vázquez, A. Khong, R. J. Cross, J. Phys. Chem., 1996, 100, 9197; K. Yamamoto, M. Saunders, A. Khong, R. J. Cross, M. Grayson, M. L. Gross, A. F. Benedetto, R. B. Weisman, J. Am. Chem. Soc., 1999, 121, 1591; M. S. Syamala, R. J. Cross, M. Saunders, J. Am. Chem. Soc., 2002, 124, 6216.

10018 Y. Rubin, Chem. Eur. J., 1997, 3, 1009; Y. Rubin, Top. Curr. Chem., 1999, 199, 67; J.-F. Nierengarten, Angew. Chem., Int. Ed., 2001, 40, 2973.

19 J. C. Hummelen, M. Prato, F. Wudl, J. Am. Chem. Soc., 1995, 117, 7003.

10520 Private communication from H. A. Jiménez-Vázquez, R. J. Cross, and M. Saunders.

21 M.-J. Arce, A. L. Viado, Y.-Z. An, S. I. Khan, Y. Rubin, J. Am. Chem. Soc., 1996, 118, 3775.

22 G. Schick, T. Jarrosson, Y. Rubin, Angew. Chem., Int. Ed., 1999, 38 2360.

23 Y. Rubin, T. Jarrosson, G.-W. Wang, M. D. Bartberger, K. N. Houk, G. Schick, M. Saunders, R. J. Cross, Angew. Chem., Int. Ed., 2001, 40, 1543 .

24 S.-C. Chuang, F. R. Clemente, S. I. Khan, K. N. Houk, Y. Rubin, Org. Lett., 2006, 8, 4525; M. Sander, T. Jarrosson, S.-C. Chuang, S. I. Khan, Y. Rubin, J. Org. Chem., 2007, 72, 2724.

25 Y. Murata, M. Murata, K. Komatsu, Chem. Eur. J., 2003, 9, 1600.

26 H. Inoue, H. Yamaguchi, T. Suzuki, T. Akasaka, S. Murata, Synlett, $2000,1178$.

2027 H. Inoue, H. Yamaguchi, S.-i. Iwamatsu, T. Uozaki, T. Suzuki, T. Akasaka, S. Nagase, S. Murata, Tetrahedron Lett., 2001, 42, 895.

28 In exactly the same way, the eight-membered ring of a benzoanalogue of compound 2 has also been expanded to a 12membered ring by photo-oxidation: Y. Murata, K. Komatsu, Chem.

125 Lett., 2001, 896; Y. Murata, M. Murata, K. Komatsu, J. Org. Chem., $2001,66,8187$.

29 S.-i. Iwamatsu, S. Murata, Synlett, 2005, 2117.

30 S.-i. Iwamatsu, F. Ono, S. Murata, Chem. Commun., 2003, 1268

31 S.-i. Iwamatsu, S. Murata, Y. Andoh, M. Minoura, K. Kobayashi, N. Mizorogi, S. Nagase, J. Org. Chem., 2005, 70, 4820

32 S.-i. Iwamatsu, T. Uozaki, K. Kobayashi, S. Re, S. Nagase, S. Murata, J. Am. Chem. Soc., 2004, 126, 2668 
33 S.-i. Iwamatsu, C. M. Stanisky, R. J. Cross, M. Saunders, N. Mizorogi, S. Nagase, S. Murata, Angew. Chem., Int. Ed., 2006, 45, 5337.

34 Z. Xiao, J. Yao, D. Yang, F. Wang, S. Huang, L. Gan, Z. Jia, Z. Jiang,

X. Yang, B. Zheng, G. Yuan, S. Zhang, Z. Wang, J. Am. Chem. Soc. 2007, 129, 16149

35 F. Wang, Z. Xiao, Z. Yao, Z. Jia, S. Huang, L. Gan, J. Zhou, G. Yuan, S. Zhang, J. Org. Chem., 2006, 71, 4374.

36 S. Huang, Z. Xiao, F. Wang, L. Gan, X. Zhang, X. Hu, S. Zhang, M.

Lu, Q. Pan, L. Xu, J. Org. Chem., 2004, 69, 2442.

37 The molecules of $\mathbf{2 6}$ were directly observed by STM: S. Yoshimoto, E. Tsutsumi, Y. Honda, Y. Murata, M. Murata, K. Komatsu, O. Ito, K. Itaya, Angew. Chem., Int. Ed., 2004, 43, 3044; S. Yoshimoto, Y. Honda, Y. Murata, M. Murata, K. Komatsu, O. Ito, K. Itaya. J. Phys. Chem. B, 2005, 109, 8547.

38 Y. Murata, M. Murata, K. Komatsu, J. Am. Chem. Soc., 2003, 125, 7152.

39 S.-C. Chuang, Y. Murata, M. Murata, S. Mori, S. Maeda, F. Tanabe, K. Komatsu, Chem. Commun., 2007, 1278.

2040 For observation of the encapsulated $\mathrm{H}_{2}$ molecule of $\mathrm{H}_{2} @ 26$ by solidstate NMR, see: M. Carravetta, Y. Murata, M. Murata, I. Heinmaa, R. Stern, A. Tontcheva, A. Samoson, Y. Rubin, K. Komatsu, M. H. Levitt, J. Am. Chem. Soc., 2004, 126, 4092.

41 H. Sawa, Y. Wakabayashi, Y. Murata, M. Murata, K. Komatsu, Angew. Chem., Int. Ed., 2005, 44, 1981.

42 S.-C. Chuang, Y. Murata, M. Murata, K. Komatsu, J. Org. Chem., 2007, 72, 6447.

43 C. M. Stanisky, R. J. Cross, M. Saunders, M. Murata, Y. Murata, K. Komatsu, J. Am. Chem. Soc., 2005, 127, 299.

3044 S.-C. Chuang, Y. Murata, M. Murata, K. Komatsu, Chem. Commun., 2007, 1751.

45 A. Khong, H. A. Jiménez-Vázquez, M. Saunders, R. J. Cross, J. Laskin, T. Peres, C. Lifshitz, R. Strongin, A. B. Smith III, J. Am. Chem. Soc., 1998, 120, 6380; J. Laskin, T. Peres, C. Lifshitz, M. Saunders, R. J. Cross, A. Khong, Chem. Phys. Lett., 1998, 285, 7.

46 Y. Murata, S. Maeda, M. Murata, K. Komatsu, J. Am. Chem. Soc., 2008, 130, 6702 .

47 K. Komatsu, M. Murata, Y. Murata, Science, 2005, 307, 238.

48 K. Komatsu, Y. Murata, Chem. Lett., 2005, 34, 886.

4049 M. Murata, Y. Murata, K. Komatsu, J. Am. Chem. Soc., 2006, 128, 8024 .

50 K. Komatsu, Bull. Chem. Soc. Jpn, 2007, 80, 2285.

51 Carbon-Rich Compounds - From Molecules to Materials, eds. M. M. Haley, R. R. Tykwinski, Wiley-VCH, Weinheim, 2006, pp 383-420.

4552 J. E. McMurry, Chem. Rev., 1989, 89, 1513.

53 D. Bakowies, W. Thiel, Chem. Phys., 1991, 151, 309.

54 Q. Xie, E. Pérez-Cordero, L. Echegoyen, J. Am. Chem. Soc., 1992, 114, 3978.

55 G.-W. Wang, K. Komatsu, Y. Murata, M. Shiro, Nature, 1997, 387, 583.

56 K. Komatsu, G.-W. Wang, Y. Murata, T. Tanaka, K. Fujiwara, J. Org. Chem., 1998, 63, 9358; K. Fujiwara, K. Komatsu, G.-W. Wang, T. Tanaka, K. Hirata, K. Yamamoto, M. Saunders, J. Am. Chem. Soc., 2001, 123, 10715.

${ }_{55} 57$ Y. Matsuo, H. Isobe, T. Tanaka, Y. Murata, M. Murata, K. Komatsu, E. Nakamura, J. Am. Chem. Soc., 2005, 127, 17148.

58 R. Subramanian, K. M. Kadish, M. N. Vijayashree, X. Gao, M. T. Jones, J. Phys. Chem., 1996, 100, 16327; S. Fukuzumi, T. Suenobu, T. Hirasaka, R. Arakawa, K. M. Kadish, J. Am. Chem. Soc., 1998,

60 120, 9220; Y.-H. Zhu, L.-C. Song, Q.-M. Hu, C.-M. Li, Org. Lett., 1999, 1, 1693.

59 A. Hirsch, Z. Chen, H. Jiao, Angew. Chem. Int. Ed., 2000, 39, 3915.

60 M. Murata, Y. Ochi, F. Tanabe, K. Komatsu, Y. Murata, Angew. Chem., Int. Ed., 2008, 47, 2039.

6561 E. Allard, L. Riviere, J. Delaunay, D. Dubois, J. Cousseau, Tetrahedron Lett., 1999, 40, 7223; E. Allard, J. Delaunay, F. Cheng, J. Cousseau, J. Ordfflna, G. Javier, Org. Lett., 2001, 3, 3503.

62 P. v. R. Schleyer, C. Maerker, A. Dransfeld, H. Jiao, N. J. R. v. E. Hommes, J. Am. Chem. Soc., 1996, 118, 6317.

7063 T. Kitagawa, H. Sakamoto, K. Takeuchi, J. Am. Chem. Soc., 1999, 121, 4298.
64 Y. Murata, K. Motoyama, K. Komatsu, T. S. M. Wan, Tetrahedron, 1996, 52, 5077.

65 M. Murata, Y. Ochi, T. Kitagawa, K. Komatsu, Y. Murata, Chem. Asian J., 2008, 3, in press.

66 E. Sartori, M. Ruzzi, N. J. Turro, J. D. Decatur, D. C. Doetschman, R. G. Lawler, A. L. Buchachenko, Y. Murata, K. Komatsu, J. Am. Chem. Soc., 2006, 128, 14752.

67 J. López-Gejo, A. A. Martí, M. Ruzzi, S. Jockusch, K. Komatsu, F. Tanabe, Y. Murata, N. J. Turro, J. Am. Chem. Soc., 2007, 129, 14554.

68 E. Sartori, M. Ruzzi, N. J. Turro, K. Komatsu, Y. Murata, R. G. Lawler, A. L. Buchachenko, J. Am. Chem. Soc., 2008, 130, 2221. 